\title{
Clinical evaluation of paired compomer and glass ionomer restorations in primary molars: final results after 42 months
}

\author{
R. R. Welbury, ${ }^{1}$ A. J. Shaw, ${ }^{2}$ J. J. Murray, ${ }^{3}$ P. H. Gordon, ${ }^{4}$ and J. F. McCabe, ${ }^{5}$
}

\begin{abstract}
Objectives To undertake a clinical trial comparing the efficiency of a compomer restoration with a glass ionomer restoration in the management of caries in primary molar teeth. Design Subjects were admitted to the trial if they required at least one pair of restorations in primary molar teeth.

Setting Department of Child Dental Health, Newcastle Dental Hospital and School.

Subject Twenty nine children, aged 4-9 years, had 56 pairs of restorations placed between January 1995 and November 1997.

Method The durability of the restorations was assessed during a 42-month follow-up period using modified United States Public Health Service criteria. Survival analysis and the McNemar paired test were used to compare the performance of the two restorative materials.

Results The compomer restorations had a higher mean survival time (42 months, SE 1.40) compared with 37 months (SE 1.90) for the glass ionomer restorations and this was significant at the $5 \%$ level. The compomer also performed significantly better in terms of anatomical form, marginal integrity, cavo surface discoloration and maintenance of interproximal contact.

Conclusions The present trial demonstrated that Dyract compomer performed significantly better than Chemfil Superior a glass ionomer cement for all modified United States Public Health Service criteria over a period of 42 months.
\end{abstract}

\footnotetext{
Techniques used to restore primary molar teeth have changed 1 over the past decade as new adhesive materials have been developed. Stainless steel or nickel chrome preformed crowns provide the most durable restoration, often surviving until the tooth exfoliates. ${ }^{1}$ The durability of other restorative materials are usually compared with dental amalgam. Composite resins in the short term are as durable as amalgam but after 6 years have a failure rate of $62 \%$ compared with $20 \%$ for amalgam after 5 years. ${ }^{2}$ Conventional glass ionomer cements on the other hand only have a mean survival time of 33 months compared with 41 months for amalgam. ${ }^{3}$ Ketac Silver (ESPE GMbH, Seefeld/Oberbay, Germany)

${ }^{1}$ Consultant, ${ }^{2}$ Senior Registrar, ${ }^{3}$ Professor, ${ }^{4}$ Senior Lecturer, Department of Child Dental Health, ${ }^{5}$ Professor, Department of Dental Materials Science, Dental Hospital and School, Framlington Place, Newcastle upon Tyne NE2 4BW Correspondence to: R. R. Welbury; R.R.Welbury@ncl.ac.uk

REFEREED PAPER

Received 14.10.99; accepted 26.04.00

(C) British Dental Journal 2000; 189: 93-97
}

a glass cermet achieved a mean survival time of 20 months over a 2.5 year period. 4

Glass ionomer cements, despite having a lower mean survival time compared with amalgam, provide a means of restoring primary molars with minimal destruction of tooth tissues. ${ }^{3}$ The search for improvements to the mechanical properties of glass ionomer cements led to the incorporation of light cured resin components to give 'resin modified glass ionomer cements' and subsequently 'poly acid modified resin composites' or 'compomers'.

Compomers were marketed in the 1990s to overcome the technique-sensitive mixing and handling properties of resin modified glass ionomer cements. They contain acid-decomposable glass and acidic, polymerisable monomers substituting the poly alkenoic acid polymers. McLean et al. ${ }^{5}$ suggested the term polyacid modified resin composites for these materials but they are commonly termed 'compomers'. Unlike glass ionomer cements and resin modified glass ionomer cements they will not set in the dark as there is insufficient water present to encourage any significant acid-base setting. The dominant setting reaction is resinous photopolymerisation.

Compomer materials combine the advantages of both glass ionomer cements and resin composites and their physical properties are similar to those of resin composites. ${ }^{6}$ In vitro evaluations have shown high bond strengths for compomers to both enamel and dentine. ${ }^{7,8}$ The compomer materials release fluoride but to a lower degree than the glass ionomer cements. ${ }^{9}$

Recent research has indicated that compomers may prove to be as durable as amalgam for the restoration of primary molar teeth. ${ }^{9-14}$ This paper reports a clinical trial comparing the efficacy of a compomer restoration with a conventional glass ionomer cement (GIC) restoration in occlusal and approximal cavities in primary molars after a follow up period of up to 42 months.

\section{Materials and Methods}

The materials used for the study were Dyract (Dentsply De Trey $\mathrm{GmbH}$, Konstanz, Germany), a compomer dispensed in compules, and Chemfil Superior (Dentsply De Trey GmbH, Konstanz, Germany) an encapsulated glass ionomer cement.

Patients attending the Department of Child Dental Health at Newcastle Dental Hospital for routine restorative care were assessed for inclusion in the trial. Subjects were admitted to the trial if they required at least one pair of restorations in their primary molar teeth. Paired cavities could either be occlusal or approximal in nature. The restorations comprising any given pair were always placed in different quadrants in any individual. 


\section{Table 1 Direct clinical evaluation criteria (modified Ryge criteria)}

Wear/Anatomic Form

1 Restoration is continuous with existing anatomical form.

2 Restoration is discontinuous with existing anatomical form, but missing material is not sufficient to expose dentin or base.

3 Sufficient material lost to expose dentin or base.

Marginal Integrity

1 Explorer does not catch and/or no crevice is visible.

2 Explorer catches and crevice is visible, but no exposure of dentin or base and restoration is not mobile.

3 Explorer penetrates crevice, defect extends to dentino-enamel junction. 4 Restoration is fractured, mobile or missing (in part or in toto).

Cavosurface Marginal Discoloration

1 No visual evidence of marginal discoloration.

2 Marginal discoloration has not penetrated in pulpal direction.

3 Marginal discoloration has penetrated in pulpal direction.

Recurrent Caries

1 No caries present

2 Caries present associated with restoration.

Surface Texture

1 Surface texture similar to polished enamel.

2 Surface texture gritty (similar to white stone).

3 Coarse surface pitting.

Maintenance of Interproximal Contact

1 Proximal contact is present.

2 Proximal contact is light but present.

3 No proximal contact.

0 No adjacent proximal surface.

Post-operative Sensitivity

1 No known sensitivity to hot, cold and biting stimuli.

2 Moderate sensitivity to hot, cold and biting stimuli; no replacement of restoration required.

3 Severe sensitivity: replacement of restoration required.

Only new cavities were suitable for inclusion in the trial. Site specificity for the two restorative materials was allocated using a random permutated block design with a block size of ten. A cavity was deemed unsuitable for the trial if the tooth could only satisfactorily be restored using a pre-formed crown.

Between January 1995 and November 1997, 56 pairs of restorations ( 31 occlusal, 25 approximal) were placed in 29 children aged $4-9$ years ( mean $=6.7$ years) and assessed at regular intervals thereafter. Two clinicians were involved in the trial, clinician 1 (RRW) placed 50 pairs of restorations and clinician 2 (AJS) placed 6 pairs. Thirty-five pairs of restorations were placed under general anaesthetic and 21 pairs under local anaesthetic.

Having been assessed as suitable for inclusion in the trial, all patients were treated as follows: under general anaesthetic, both restorations of a pair were completed. Under local anaesthetic, one restoration of a pair was completed at one visit and the remaining restoration at a subsequent visit. Isolation was achieved with cotton wool rolls, dry-tips and saliva ejector. Occlusal cavities were prepared which only removed carious tissue and did not extend into non-carious fissures. Approximal cavities were prepared to an adhesive design (box-shape combined with a short bevel). A metal matrix was then placed and secured with a wooden wedge.

Dyract compomer restorations were placed according to the manufacturer's instructions without acid etching using two layers of 'Prime and Bond' 2.1 strictly following drying and curing instructions for the bond (first layer: 30 seconds undisturbed, 10 seconds gentle air dry, 10 seconds light cure; second layer: dry after application for 10 seconds, light cure 10 seconds) and curing instructions for the compomer (40 seconds light cure). The compomer was placed in horizontal layers not exceeding a thickness of $2 \mathrm{~mm}$ to allow proper polymerisation of the material. After removal of the matrix band the restorations were finished with composite finishing stones and multi-fluted tungsten carbide burs. In accord with the manufacturer's instructions there was no acid etching and washing of the prepared cavity, prior to Prime and Bond 2.1 placement.

Chemfil Superior GIC was placed according to manufacturer's instructions after mixing in a Silamat (Vivadent). No cleansing or conditioning agent was used prior to placement in accord with the manufacturer's instructions at the beginning of the trial in January 1995. After 5 minutes, the occlusion was checked and any excess removed with a sharp excavator. The restoration was then covered in Spectrum TPH (Dentsply Do Trey G 6H, Konstanz, Germany) unfilled resin and light cured for 20 seconds.

Direct evaluations of the restorations were accomplished by one investigator (RRW). Using modified Ryge USPHS criteria, ${ }^{15}$ each restoration was assessed at baseline ( 1 month after placement) and at 6 monthly intervals for wear/anatomical form, marginal integrity, cavosurface marginal discolouration, recurrent caries, surface texture, maintenance of interproximal contact (approximal restorations only) and post-operative sensitivity (Table 1 ).

Value 1 indicates a clinically ideal situation. Value 2 (apart from caries) indicates a clinically acceptable situation. Value 3 indicates a clinically unacceptable situation which usually requires replacement of the restoration. Value 4 indicates a clinically unacceptable situation because of fracture, mobility or loss of the restoration which makes it necessary to replace the restoration

Interproximal contact areas were graded by passing unwaxed dental floss through the promimal contact. Value 0 indicates the absence of an adjacent approximal surface.

Post-operative sensitivity was assessed by questioning the patients at baseline.

Cavosurface discolouration was graded as 2 if there was no adjacent discolouration of enamel and 3 if enamel discolouration was evident.

Surface texture was assessed visually and by probe, and graded in accord with the modified Ryge criteria.

Statistical comparison of Dyract and Chemfil Superior restorations for the assessment criteria was by survival analysis techniques (BMDP University of California) and by McNemar testing giving a chi-squared statistic with one degree of freedom after arranging the paired data into $2 \times 2$ tables according to which material failed first.

The power of the study, when comparing occlusal and approximal restorations, gave an $80 \%$ chance of a true difference of $25 \%$ being found significant at the $5 \%$ level. When comparing one material against the other, with occlusal and approximal restorations pooled, the power of the study gives an $80 \%$ chance of finding a $15 \%$ difference to be significant at the $5 \%$ level. ${ }^{16}$

\section{Results}

Between baseline and the censor date (30 November 1998) the number of pairs of restorations assessed at 6-monthly intervals is shown in Table 2. Between baseline and 42 months the history of the 56 pairs of restorations is shown in Table 3.

The results (percentages) of the direct clinical evaluation (baseline, 6 months, 1 year, 18 months, 2 years, 30 months, 3 years and 42 months) are presented in Table 4.

Fifteen restorations failed during the follow-up period. A restoration was graded as failed if it had a score of 3 for anatomic form, 3 or 4 for marginal integrity, or 2 for caries. Of these 15 restoration failures $12(80 \%)$ were Chemfil Superior and $3(20 \%)$ were Dyract. The reasons for failure are shown in Table 5.

For an anatomical form score of 2 (AF2) Dyract performed significantly better than Chemfil Superior in both statistical methods $(P<0.0001$ Breslow; $P<0.001$ McNemar $)$. Chemfil restorations had a mean survival time (MST) to reach AF2 of 8 months compared with 25 months for Dyract. 
Table 2 Number of pairs of restorations assessed at each 6-monthly interval

\begin{tabular}{cccc}
\hline $\begin{array}{c}\text { Months after } \\
\text { placement }\end{array}$ & Occlusal & $\begin{array}{c}\text { Pairs } \\
\text { Approximal }\end{array}$ & $\begin{array}{l}\text { Pairs } \\
\text { total }\end{array}$ \\
\hline Baseline & 31 & 25 & 56 \\
6 & 31 & 25 & 56 \\
12 & 27 & 22 & 49 \\
18 & 25 & 18 & 43 \\
24 & 12 & 14 & 26 \\
30 & 12 & 12 & 24 \\
36 & 11 & 4 & 15
\end{tabular}

Table 3 History of the 56 pairs of restorations

\begin{tabular}{ll}
\hline Followed to censor date & 20 pairs \\
Exfoliated prior to censor date & 15 pairs \\
$\begin{array}{l}\text { Failure of one/both restoration } \\
\text { prior to censor date }\end{array}$ & 14 pairs * \\
$\begin{array}{l}\text { Failure because of caries elsewhere on } \\
\text { the tooth and therefore withdrawn }\end{array}$ & 1 pair \\
Lost to follow up (2 children) & 6 pairs
\end{tabular}

* In one pair of restorations both restorations failed simultaneously giving a total of 15 failed restorations (Table 5).
For a marginal integrity score of 2 (MI2) there was a significant difference in the rate of loss of marginal integrity for the two materials, with Dyract performing better than Chemfil $(P<0.0001$ Breslow; $P<0.001$ McNemar). Chemfil restorations had an MST to reach MI2 of 23 months compared with 36 months for Dyract.

The cumulative survival curves for overall failure are shown in Figure 1. There was a significant difference in performance between the two materials throughout the duration of the study favouring Dyract $(P=0.0125$ Breslow; $P<0.05 \mathrm{McNemar})$. The MST for Dyract was 42 months (SE 1.40) and for Chemfil Superior was 37 months (SE 1.90). The MST of each material was not significantly different in occlusal or approximal cavities.

Dyract also performed significantly better than Chemfil Superior with regard to caries $(P<0.05$ Breslow and McNemar); cavosurface marginal discolouration $(P<0.001$ Breslow and McNemar $)$; maintenance of interproximal contact in approximal restorations $(P<0.01$ McNemar); and surface texture $(P<0.001 \mathrm{McNemar})$. Neither material exhibited any postoperative sensitivity.

\section{Discussion}

The requirements for a restorative material in the primary dentition are different from those in the permanent dentition and a material which is ideal for one may not be ideal for the other. Primary teeth, in terms of human life span, are only temporary having a maximum normal life of 8-9 years. Consequently a restoration will only have to last for a limited time in function in the oral environment. Previous authors have postulated that some adhesive materials are capable of fulfilling this requirement. ${ }^{3,13,17}$ In addition there are other potential advantages associated with the use of adhesive materials in children. They allow

Table 4 Ryge criteria pairs of restorations in percentages (Baseline: $n=56$; 6 months: $n=56$; 1 Year: $n=49 ; 2$ Years: $n=26$; 30 months: $n=24 ; 3$ years: $n=15 ; 42$ months: $n=8$ )

\begin{tabular}{|c|c|c|c|c|c|c|c|c|c|c|c|c|c|c|c|c|c|}
\hline & & \multicolumn{4}{|c|}{$\begin{array}{l}\text { Baseline (56) } \\
\text { Score }\end{array}$} & \multicolumn{4}{|c|}{$\begin{array}{l}6 \text { Months (56) } \\
\text { Score }\end{array}$} & \multicolumn{4}{|c|}{$\begin{array}{l}1 \text { Year (49) } \\
\text { Score }\end{array}$} & \multicolumn{4}{|c|}{18 Months (43) } \\
\hline & & 1 & 2 & 3 & 4 & 1 & 2 & 3 & 4 & 1 & 2 & 3 & 4 & 1 & 2 & 3 & 4 \\
\hline \multirow[t]{2}{*}{$\mathrm{AF}$} & D & 100 & 0 & 0 & 0 & 98 & 2 & 0 & 0 & 69 & 29 & 2 & 0 & 58 & 42 & 0 & 0 \\
\hline & C & 100 & 0 & 0 & 0 & 43 & 55 & 2 & 0 & 16 & 77 & 7 & 0 & 12 & 85 & 3 & 0 \\
\hline \multirow[t]{2}{*}{ Ml } & D & 100 & 0 & 0 & 0 & 100 & 0 & 0 & 0 & 96 & 2 & 2 & 0 & 95 & 5 & 0 & 0 \\
\hline & C & 100 & 0 & 0 & 0 & 87 & 11 & 2 & 0 & 80 & 12 & 3 & 5 & 24 & 72 & 4 & 0 \\
\hline \multirow[t]{2}{*}{ CSMD } & $D$ & 100 & 0 & 0 & 0 & 100 & 0 & 0 & 0 & 100 & 0 & 0 & 0 & 98 & 2 & 0 & 0 \\
\hline & $C$ & 100 & 0 & 0 & 0 & 96 & 2 & 2 & 0 & 95 & 5 & 0 & 0 & 86 & 14 & 0 & 0 \\
\hline \multirow[t]{2}{*}{ Caries } & D & 100 & 0 & 0 & 0 & 100 & 0 & 0 & 0 & 100 & 0 & 0 & 0 & 100 & 0 & 0 & 0 \\
\hline & C & 100 & 0 & 0 & 0 & 93 & 7 & 0 & 0 & 97 & 3 & 0 & 0 & 91 & 9 & 0 & 0 \\
\hline \multirow[t]{2}{*}{ IPC } & D & 100 & 0 & 0 & 0 & 100 & 0 & 0 & 0 & 86 & 9 & 5 & 0 & 72 & 6 & 0 & $22^{*}$ \\
\hline & C & 100 & 0 & 0 & 0 & 84 & 12 & 4 & 0 & 73 & 18 & 9 & 0 & 39 & 28 & 0 & $33^{*}$ \\
\hline \multirow[t]{2}{*}{ ST } & $D$ & 100 & 0 & 0 & 0 & 100 & 0 & 0 & 0 & 100 & 0 & 0 & 0 & 97 & 0 & 3 & 0 \\
\hline & $C$ & 100 & 0 & 0 & 0 & 5 & 95 & 0 & 0 & 0 & 96 & 4 & 0 & 4 & 91 & 5 & 0 \\
\hline \multirow[t]{4}{*}{ POS } & D & 100 & 0 & 0 & 0 & 0 & 0 & 0 & 0 & 0 & 0 & 0 & 0 & 0 & 0 & 0 & 0 \\
\hline & C & 100 & 0 & 0 & 0 & 0 & 0 & 0 & 0 & 0 & 0 & 0 & 0 & 0 & 0 & 0 & 0 \\
\hline & & \multicolumn{4}{|c|}{$\begin{array}{c}2 \text { years }(26) \\
\text { Score }\end{array}$} & \multicolumn{4}{|c|}{$\begin{array}{c}30 \text { Months (24) } \\
\text { Score }\end{array}$} & \multicolumn{4}{|c|}{$\begin{array}{l}3 \text { Years (15) } \\
\text { Score }\end{array}$} & \multicolumn{4}{|c|}{$\begin{array}{l}42 \text { Months (8) } \\
\text { Score }\end{array}$} \\
\hline & & 1 & 2 & 3 & 4 & 1 & 2 & 3 & 4 & 1 & $2^{5}$ & 3 & 4 & 1 & $2^{x}$ & 3 & 4 \\
\hline \multirow[t]{2}{*}{$\mathrm{AF}$} & D & 27 & 69 & 4 & 0 & 38 & 62 & 0 & 0 & 53 & 47 & 0 & 0 & 92 & 8 & 0 & 0 \\
\hline & C & 8 & 88 & 4 & 0 & 8 & 92 & 0 & 0 & 18 & 82 & 0 & 0 & 25 & 75 & 0 & 0 \\
\hline \multirow[t]{2}{*}{ Ml } & D & 92 & 0 & 4 & 4 & 100 & 0 & 0 & 0 & 88 & 12 & 0 & 0 & 100 & 0 & 0 & 0 \\
\hline & C & 63 & 33 & 4 & 0 & 75 & 25 & 0 & 0 & 54 & 46 & 0 & 0 & 42 & 58 & 0 & 0 \\
\hline \multirow[t]{2}{*}{ CSMD } & $D$ & 96 & 4 & 0 & 0 & 96 & 4 & 0 & 0 & 100 & 0 & 0 & 0 & 100 & 0 & 0 & 0 \\
\hline & C & 77 & 23 & 0 & 0 & 75 & 25 & 0 & 0 & 75 & 25 & 0 & 0 & 67 & 23 & 0 & 0 \\
\hline \multirow[t]{2}{*}{ Caries } & D & 100 & 0 & 0 & 0 & 100 & 0 & 0 & 0 & 100 & 0 & 0 & 0 & 100 & 0 & 0 & 0 \\
\hline & C & 100 & 0 & 0 & 0 & 100 & 0 & 0 & 0 & 100 & 0 & 0 & 0 & 100 & 0 & 0 & 0 \\
\hline \multirow[t]{2}{*}{ IPC } & $D$ & 71 & 8 & 0 & $21^{*}$ & 42 & 0 & 0 & $58^{*}$ & 50 & 0 & 0 & $50^{*}$ & 50 & 0 & 0 & $50^{*}$ \\
\hline & C & 28 & 36 & 0 & $36^{*}$ & 25 & 8 & 0 & $67^{*}$ & 0 & 50 & 0 & $50^{*}$ & 0 & 50 & 0 & $50^{*}$ \\
\hline \multirow[t]{2}{*}{ ST } & $D$ & 96 & 0 & 4 & 0 & 100 & 0 & 0 & 0 & 100 & 0 & 0 & 0 & 100 & 0 & 0 & 0 \\
\hline & C & 7 & 86 & 7 & 0 & 4 & 96 & 0 & 0 & 13 & 87 & 0 & 0 & 0 & 100 & 0 & 0 \\
\hline \multirow[t]{2}{*}{ POS } & D & 0 & 0 & 0 & 0 & 0 & 0 & 0 & 0 & 0 & 0 & 0 & 0 & 0 & 0 & 0 & 0 \\
\hline & C & 0 & 0 & 0 & 0 & 0 & 0 & 0 & 0 & 0 & 0 & 0 & 0 & 0 & 0 & 0 & 0 \\
\hline
\end{tabular}

*Represent ' 0 ' scoring category for IPC 
Table 5 The reasons for failure of individual restorations

\begin{tabular}{lcc}
\hline & Dyract & Chemfil \\
\hline Total loss of restoration & 1 & 3 \\
Partial loss of restorative material & 1 & 3 \\
Fracture of restoration & 1 & 0 \\
Recurrent caries & 0 & 6 \\
\hline Total & 3 & 12 \\
\hline
\end{tabular}

Note: 15 restorations failed but one pair failed together making a total of 14 pairs that failed (Table 3)

less destructive cavity preparation and a smaller restoration; this in turn would reduce treatment time, and may mean that local analgesia would not be necessary. Also of importance is the longterm fluoride release from glass ionomer, resin modified glass ionomer cements and polyacid modified composite resins. These materials also have the ability to be recharged by exposure to fluoride solutions and gels. ${ }^{18}$

The results of this study were analysed both by McNemar paired testing which follows each pair of restorations to failure (by defined criteria) of one or both restorations and by survival analysis. ${ }^{19}$ Survival analysis allows accurate comparison of the two techniques/ materials during the whole follow up period rather than at specific time intervals. Comparison of the two materials is performed by calculating the significance of the differences between the two survival curves, using the Log Rank Test, over the whole of their length. This provides an accurate picture of the relative performance of the compared materials over the study period.

On all assessment criteria (Table 1) Dyract performed statistically better than Chemfil Superior. Dyract restorations were superior in maintaining surface texture, interproximal contact, anatomical form, and marginal integrity; and developed less cavosurface marginal discolouration; and caries. It is interesting to note that six Chemfil restorations failed because of recurrent caries compared with no Dyract restorations (Table 5). This in spite of the fact that there is more fluoride available for release in conventional glass ionomer cements than compomers in vitro. ${ }^{9}$ This may cast doubt upon the clinical benefit of such fluoride availability. The overall failure pattern which gave an MST of 42 months (SE 1.40) for Dyract and an MST of 37 months (SE 1.90) for Chemfil Superior allows comparison with other materials, using the same assessment criteria, in previous work in this field.

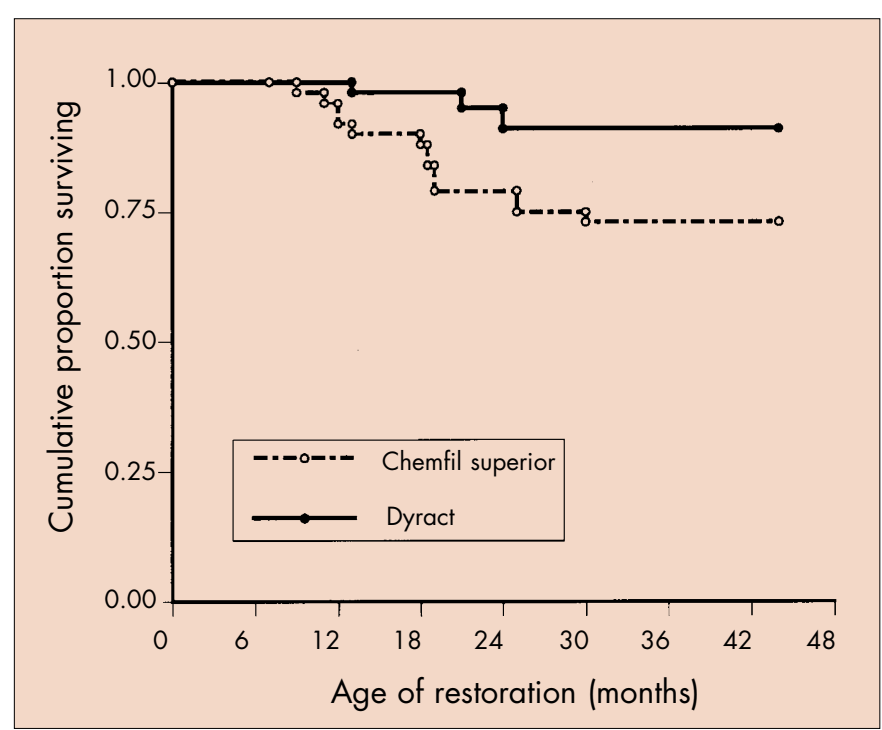

Fig. 1 Cumulative survival curves for overall failure for Chemfil Superior and Dyract

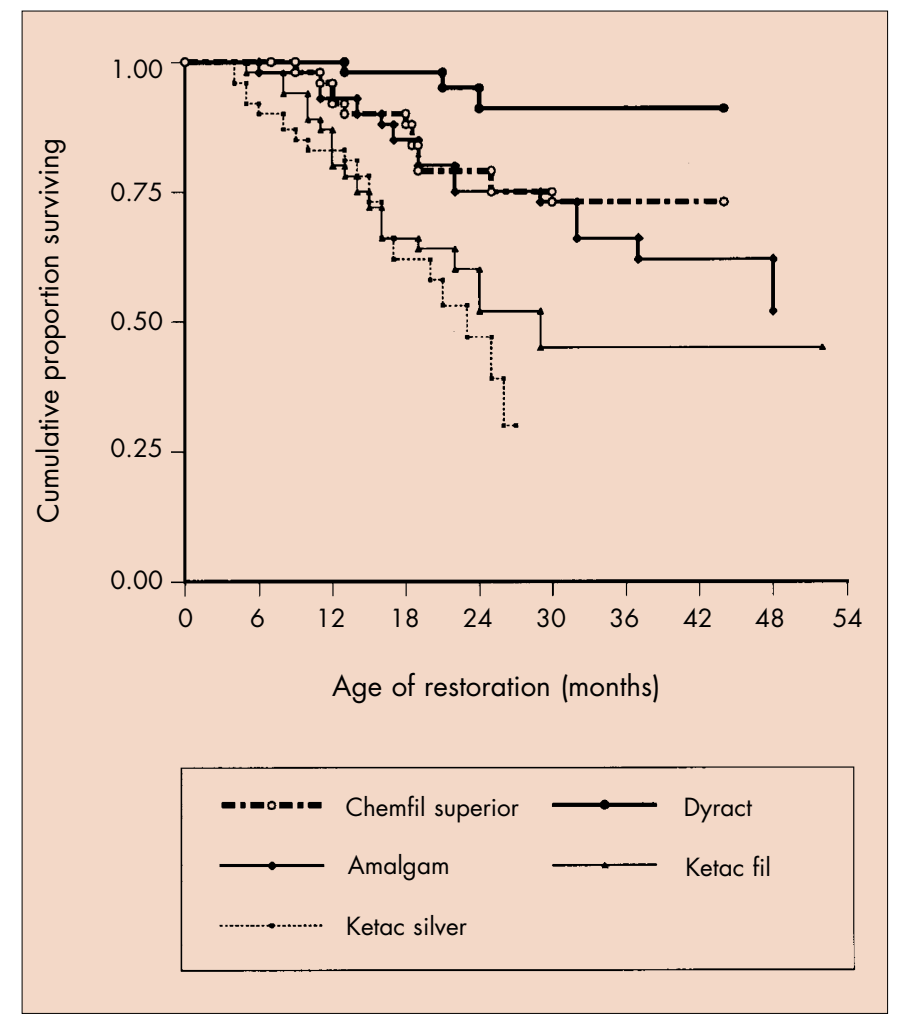

Fig. 2 Cumulative survival curves for overall failure for five materials, produced by combining results from 1991, ${ }^{3} 1995,4$ with the present study. The methodology for the three studies was identical but conditions may have been dissimilar. This should be taken into account when comparing the studies

Before these potentially beneficial adhesive materials are more widely adopted, it must be demonstrated that their durability approaches that of dental amalgam. Figure 2 shows the survival curve produced from combining results from $1991^{3}$ (amalgam versus glass ionomer cement) and $1995^{4}$ (cermet) with the present study. From the 5 year survival curves the following Mean Survival Times can be calculated - Dyract: MST 42 months; Amalgam: MST 41.4 months; Chemfil Superior: MST 37 months; Ketac Fil: MST 33.4 months; and Ketac Silver: MST 20.3 months (Ketac Fil: ESPE GMbH, Seefeld/Oberbay, Germany). The MST for Ketac Silver must be interpreted in the light of the fact that a large proportion of restorations were 'censored' ie they survived intact at the end of the 2.5 year trial. Their MST will be an under-estimation and prediction of actual longevity is not possible.

Within the statistical confines of survival analysis, the present trial has demonstrated that an adhesive material - Dyract compomer - has a survival time comparable with amalgam from a previous clinical trial using the same assessment criteria and statistical analysis techniques. ${ }^{3}$ The results of this study are the latest in a series of clinical trials which began in 1982 and have involved the assessment of the durability of 442 restorations in primary molar teeth. ${ }^{3,4}$

The conclusions to be drawn from this study are that when compomer and glass ionomer cement restorations are placed in adhesively designed occlusal and approximal cavities in primary molars, the compomer is superior in terms of anatomic form, marginal integrity, cavosurface discolouration, recurrent caries, maintenance of interproximal contact, surface texture, and overall failure. There was no reported postoperative sensitivity with either material.

The authors thank: Dentsply DcTrey GMbH Konstanz; Audio Visual Department, University of Newcastle upon Tyne; Dr Joost Roeters, University of Nijmegen, for his helpful comments. 
1 Roberts J F, Sheriff M. The fate and survival of amalgam and preformed restorations placed in specialist paediatric dental practice. Br Dent J 1990; 169: 237-244.

2 Kilpatrick N M. Durability of restorations in primary molars. J Dent 1993; 21: 67-73.

3 Welbury R R, Walls A W G, Murray J J, McCabe J F. The 5 year results of a clinical trial comparing a glass polyalkenoate (ionomer) cement restoration with an amalgam restoration. Br Dent J 1991; 170: 177-181.

4 Kilpatrick N M, Murray J J, McCabe J F. The use of a reinforced glassionomer cermet for the restoration of primary molars: a clinical trial. $\mathrm{Br}$ Dent J 1995; 179: 175-179.

5 McLean J W, Nicholson J W, Wilson A D. Proposed nomenclature for glass ionomer dental cements and related materials. Quint Int 1994; 25: 587-589.

6 Attin T, Vataschki M, Hellwig E. Properties of resin-modified glass ionomer restorative materials and two poly acid-modified resin composite materials. Quint Int 1996; 27: 203-209.

7 Triana R, Prado C, Garo J, Garcia-Godoy F, Dentine bond strength of fluoride releasing materials. Am J Dent 1994; 7: 252-254.

8 Cortes O, Garcia-Godoy F, Boj J R, Bond strength of resin reinforced glass ionomer cements after enamel etching. Am J Dent 1993; 6: 299-301.

9 Shaw A J, Carrick T, McCabe J F. Fluoride release from glass ionomer and compomer restorative materials: 6 month data. J Dent 1998; 26: 355-359.

10 Welbury R R, Shaw A J, Murray J J , McCabe J F. Clinical evaluation of paired compomer and GIC restorations in primary teeth. J Dent Res 1998 SI Abs 47.

11 Andersson-Wenckert I E, Folkesson U H, van Dijken J M V. Durability of a polyacid-modified composite resin (compomer) in primary teeth. A multicenter study. Acta Odontol Scan 1997; 55: 255-260.

12 Hse K M Y, Wei S H Y. Clinical evaluation of a compomer in primary teeth: 1 year results. J Am Dent Ass 1997; 128: 1088-1096

13 Roeters J J M, Frankenmolen F, Burgersdijk R C W. Clinical evaluation of Dyract in primary molars: 3 year results. Am J Dent 1998; 3: 143-148.

14 Marks L A M, Weerheijm K L, van Amerongen W E et al. Dyract versus Tytin class II restorations in primary molars: 36 months evaluation. Caries Res 1999; 33: 387-392.

15 Ryge G. Clinical Criteria. Int Dent J 1980; 30: 347-358.

16 Machin P, Campbell M, Fayers P, Pirol A. Sample size tables for clinical studies. 2nd ed. Oxford: Blackwell, 1997.

17 Knibbs P J, Plant C G, Pearson G J. An evaluation of an anhydrous glass ionomer cement in general dental practice. Br Dent J 1986; 160: 170-173.

18 Bilgin Z, Ozalp N. Fluoride release from three different types of Glass Ionomer Cements after exposure to NaF solution and APF gel. J Clin Pediatr Dent 1998; 22: 237-241.

19 Peto R, Pike M C, Armitage P et al. Design and analysis of randomised clinical trials requiring prolonged observation of each patient. II Analysis and examples. Br J Cancer 1977; 35: 1-39. 